\title{
Timing of Transfer and Mortality in Neonates with Hypoplastic Left Heart Syndrome in California
}

\author{
Neha J. Purkey ${ }^{1}(1) \cdot$ Chen $\mathrm{Ma}^{2} \cdot$ Henry C. Lee ${ }^{2} \cdot$ Susan R. Hintz ${ }^{2} \cdot$ Gary M. Shaw ${ }^{2} \cdot$ Doff B. McElhinney $^{1,3}$. \\ Suzan L. Carmichael ${ }^{2,4}$
}

Received: 27 August 2020 / Accepted: 16 January 2021 / Published online: 3 February 2021

(c) The Author(s), under exclusive licence to Springer Science+Business Media, LLC part of Springer Nature 2021

\begin{abstract}
Maternal race/ethnicity is associated with mortality in neonates with hypoplastic left heart syndrome (HLHS). We investigated whether maternal race/ethnicity and other sociodemographic factors affect timing of transfer after birth and whether timing of transfer impacts mortality in infants with HLHS. We linked two statewide databases, the California Perinatal Quality Care Collaborative and records from the Office of Statewide Health Planning and Development, to identify cases of HLHS born between 1/1/06 and 12/31/11. Cases were divided into three groups: birth at destination hospital, transfer on day of life $0-1$ ("early transfer"), or transfer on day of life $\geq 2$ ("late transfer"). We used log-binomial regression models to estimate relative risks (RR) for timing of transfer and Cox proportional hazard models to estimate hazard ratios (HR) for mortality. We excluded infants who died within 60 days of life without intervention from the main analyses of timing of transfer, since intervention may not have been planned in these infants. Of 556 cases, 107 died without intervention (19\%) and another 52 (9\%) died within 28 days. Of the 449 included in analyses of timing of transfer, $28 \%$ were born at the destination hospital, $49 \%$ were transferred early, and $23 \%$ were transferred late. Late transfer was more likely for infants of low birthweight (RR 1.74) and infants born to US-born Hispanic (RR 1.69) and black (RR 2.45) mothers. Low birthweight (HR 1.50), low 5-min Apgar score (HR 4.69), and the presence of other major congenital anomalies (HR 3.41), but not timing of transfer, predicted neonatal mortality. Late transfer was more likely in neonates born to US-born Hispanic and black mothers but was not associated with higher mortality.
\end{abstract}

Keywords Congenital heart disease $\cdot$ Mortality rate $\cdot$ Sociodemographic factors $\cdot$ Patient management $\cdot$ Interhospital transfer

Neha J. Purkey

npurkey@stanford.edu

1 Division of Cardiology, Department of Pediatrics, Stanford University School of Medicine, Stanford, USA

2 Division of Neonatology and Developmental Medicine, Department of Pediatrics, Stanford University School of Medicine, Stanford, USA

3 Division of Pediatric Cardiac Surgery, Department of Cardiothoracic Surgery, Stanford University School of Medicine, Stanford, USA

4 Division of Maternal-Fetal Medicine and Obstetrics, Department of Obstetrics and Gynecology, Stanford University School of Medicine, Stanford, USA

\section{Introduction}

Congenital heart disease (CHD) affects approximately $1 \%$ of live births in the United States. Hypoplastic left heart syndrome (HLHS) occurs in 13 per 100,000 live births making up $1.2 \%$ of congenital heart defects in the United States [1]. While rare, HLHS is one of the most serious forms of congenital heart disease and is still associated with a high mortality rate; recent data estimate neonatal mortality to be between 23 and 30\% for HLHS [2-4]. The last four decades have seen remarkable advances in the surgical and postoperative management of infants with HLHS, but there is still important work to be done to further improve survival.

A large body of literature has associated a higher risk of mortality from HLHS and other critical congenital heart disease with certain race/ethnicities [5-13]. A few studies have linked mortality in patients with HLHS to other 
sociodemographic factors, such as poverty $[4,5,14]$ and insurance status [15]. Patient management factors have also been implicated in neonatal mortality from HLHS, including birth location [3], timing of initial surgery [16, 17], and timing of delivery $[18,19]$.

Few studies have examined the interplay of sociodemographic factors and management decisions made for infants with HLHS [20]. It is unclear if race/ethnicity or socioeconomic status impact some of these management decisions and contribute to the resulting higher risk of mortality. While patient management decisions can be indirectly linked to interhospital transfer patterns, to our knowledge, no study has directly examined timing of transfer to a surgical center and outcomes. We therefore designed a study to investigate whether maternal, infant, and care-related factors are predictive of transfer after birth and timing of transfer. As a secondary aim, we investigated whether any of these factors are predictive of mortality in infants with HLHS.

\section{Methods}

\section{Study Population}

We used linked data from two statewide databases on births in California from January 1, 2006, to December 31, 2011. The California Perinatal Quality Care Collaborative (CPQCC) prospectively collects data on infants admitted to participating neonatal intensive care units (NICUs) and includes more than $90 \%$ of all NICUs in California (cpqcc. org). CPQCC data were linked with data files from the California Office of Statewide Health Planning and Development (OSHPD) that include linked data on hospital admissions for infants from birth through 1 year of age, birth certificates, and infant death certificates. These OSHPD files are further linked to maternal data including hospitalizations during the pregnancy [21]. Linkage of maternal and infant data is successful for $>98 \%$ of live births. CPQCC and OSPHD have been linked through 2012; however, the linkage with infant death certificates through 1 year of life is only available through 2011. The OSPHD files include up to 25 diagnostic and 21 procedure ICD-9 codes per hospitalization.

Frohnert et al. previously examined the validity of ICD9-CM coding for congenital heart disease in a single center and found only $41 \%$ of ICD-9-CM coding to accurately reflect the cardiac diagnosis [22]. Additional studies in the adult congenital heart disease population have revealed similar results [23, 24]. Given the more robust nature of data collection for CQPCC, we therefore chose to use CPQCC data to identify the cases for our study [22-24]. Demographic and mortality data were then obtained from OSHPD.

We identified 773 cases that had a CPQCC code for HLHS, 67 of whom could not be linked to OSHPD data and were excluded. Of the remaining 706 infants, 55 survived to 60 days of life without a surgical or catheter-based intervention documented in CPQCC or OSHPD. These 55 infants were excluded since data errors were considered likely (either in the diagnosis or hospital discharge information); based on clinical experience, this outcome is extremely unlikely for a patient with HLHS. One patient underwent a fetal surgery and was also excluded. Of the remaining 650 infants, 556 had complete data on relevant covariates (described below) and were included in analyses (see Supplemental Fig. 1).

\section{Study Outcomes}

For the 556 cases, data in CPQCC and OSHPD were queried for a surgical or catheter-based intervention in the first 60 days of life. ICD-9 codes were manually reviewed by the first author to confirm that patients classified as "no intervention" had no evidence of a surgical or catheter-based intervention.

There were 107 infants who died within 60 days of life prior to any intervention being performed. We excluded them from our main analyses of timing of transfer; intervention may not have been performed or even planned in these infants due to the severity of their condition or family choice, which could have affected decisions to transfer them. Our primary goal was to identify factors associated with delays in transfer among infants who ultimately were well enough to undergo surgical repair and were chosen for intervention.

The remaining 449 infants who had an intervention were divided into three groups based on the day of arrival at the hospital where the intervention was performed: those who were born into the same hospital as the intervention ("not transferred"), those who arrived at the intervention hospital on day of life (DOL) 0 or 1, and those who arrived at the intervention hospital on DOL 2 or later. DOL 1 was included with DOL 0 to account for infants who were born late in the evening (infants born at 11:59 p.m. would be counted as DOL 1 by 12:01 a.m.). DOL $0-1$ therefore represents infants arriving at the intervention hospital within a maximum of $48 \mathrm{~h}$ of birth.

The second outcome we examined was infant mortality. Age at death up to 1 year of life was derived from death certificate data and described for all 556 infants. Neonatal mortality was defined as death within 28 days.

\section{Covariates}

Descriptive data about the mothers and infants were obtained from infants' birth certificates. Maternal data included age, race/ethnicity, education, payer, prenatal care, and geocoded residential addresses. Maternal addresses were geocoded 
by the California Environmental Health Tracking Program (CEHTP) Geocoding Service. We then used these geocoded maternal addresses to assign census tracts and determined census tract poverty level using the 2007-2011 American Community Survey Files. Infant data included sex, birthweight, gestational age, and 5-min Apgar score. The presence of other major non-cardiac congenital anomalies was assigned based on CPQCC data (see Supplemental Table 1 for further information).

We assigned hospital level of neonatal care for the birth and intervention hospital. Levels were based on American Academy of Pediatrics guidelines from 2012 [25]. Briefly, level I hospitals are well newborn nurseries; level II units provide care for infants born at greater than 32 weeks' gestational age and weighing at least $1500 \mathrm{~g}$; level III units provide comprehensive care for infants of all gestational ages and birth weights and include access to a full range of pediatric subspecialties; and level IV units are regional centers with 24-h access to pediatric subspecialty care and the ability to repair complex congenital conditions including cardiac disease.

\section{Analyses}

We first describe covariates, overall and then separately among the 107 infants who died prior to intervention and the remaining 449 who did not die prior to intervention. A log-binomial regression model was used to analyze predictors of transfer and generate unadjusted and adjusted estimates of relative risk (RR) among the 449 infants who did not die prior to intervention by comparing cases born into their intervention hospital to cases who were transferred. We then analyzed predictors of early transfer (DOL 0-1) compared to late transfer (DOL $\geq 2$ ). Crude (unadjusted) RRs and RRs adjusted for coviariates were estimated from these models. We selected potential covariates for multivariable models a priori, including maternal age, race/ethnicity, education, payer, census tract poverty level, infant birthweight, 5-min Apgar score, and the presence or absence of other congenital anomalies. Gestational age was excluded from multivariable models due to its close association with birthweight and higher unreported data, hospital level of care was excluded due to its close association with transfer patterns, and prenatal care was excluded due to small numbers in one of the groups. A sensitivity analysis was performed including the 107 infants who died within 60 days of life without intervention.

Finally, we conducted Cox proportional hazards analyses to identify predictors of mortality among all 556 cases at 28 days and at 1 year of life. The same covariates from the transfer model were chosen a priori with the addition of infant sex, transfer status, and day of life of arrival at intervention hospital.
This study was approved by the California Committee for the Protection of Human Subjects and Stanford University's Institutional Review Board. Analyses were performed using SAS 904 (SAS Institute, Inc., Cary, NC).

\section{Results}

Of the total cohort of 556 cases, $62 \%$ were male, $57 \%$ were born to mothers who self-identified as Hispanic, 59\% were covered by government insurance, and $32 \%$ were born to mothers with less than a high school education (Table 1). Most infants were born at term and at normal weight, and $6 \%$ also had non-cardiac congenital anomalies.

Relative to the 449 infants who did not die before intervention, the 107 infants who did tended to have similar sociodemographic characteristics but be higher risk based on clinical factors; i.e., $57 \%$ vs. $15 \%$ were of low birthweight, $43 \%$ vs. $15 \%$ were preterm, $48 \%$ vs. $5 \%$ had low 5 -min Apgar scores, and $24 \%$ vs. $<5 \%$ also had non-cardiac congenital anomalies (Table 1). Of note, $60 \%$ of these infants died within the first week of life, compared to $4 \%$ of the 449 infants who did not die before intervention.

\section{Hospital Transfer}

Of the 449 infants included in analyses of transfer, 124 (28\%) were not transferred, $220(49 \%)$ were transferred to the intervention hospital early (DOL 0-1), and 105 (23\%) were transferred to the intervention hospital late $(\mathrm{DOL} \geq 2)$ (Table 1). Of the 107 infants who did not have an intervention before they died, $<60 \%$ were not transferred, $<35 \%$ were transferred early, and $<15 \%$ were transferred later (percents are approximated to mask small cell sizes).

In multivariable analyses comparing the 325 infants who were transferred prior to intervention with the 124 infants born into the intervention hospital, infants born to foreignborn Hispanic mothers were the only group for which the 95\% confidence interval excluded 1.0 (RR 0.80) with higher likelihood of being born into a destination center (Table 2).

In multivariable analyses comparing late transfers $(\mathrm{DOL} \geq 2)$ with early transfers (DOL $0-1)$ as the reference group, late transfer was more likely for infants of low birthweight (RR 1.74) and infants born to US-born Hispanic (RR 1.69) and black (RR 2.45) mothers; 95\% confidence intervals for these RRs excluded 1.0 (Table 3).

Multivariable analyses were repeated for the total cohort of 556 infants (including the 107 who died prior to intervention), comparing the 369 infants who were transferred to the 187 infants who were not; results were similar to those for the main analyses with one noted exception (Supplemental Tables 2, 3). Low 5-min Apgar score was associated with reduced risk of any transfer and late transfer; the respective 
Table 1 Characteristics of infants with hypoplastic left heart syndrome born in California from 2006 to 2011

\begin{tabular}{|c|c|c|c|}
\hline & Total & $\begin{array}{l}\text { Infants with } \\
\text { interventions }\end{array}$ & $\begin{array}{l}\text { Infants who died } \\
\text { prior to interven- } \\
\text { tion }\end{array}$ \\
\hline & $\%(n=556)$ & $\%(n=449)$ & $\%(n=107)$ \\
\hline \multicolumn{4}{|l|}{ Infant sex } \\
\hline Male & 62 & 64 & 54 \\
\hline Female & 38 & 36 & 46 \\
\hline \multicolumn{4}{|l|}{ Birthweight (g) } \\
\hline$<2500$ & 23 & 15 & 57 \\
\hline$\geq 2500$ & 77 & 85 & 43 \\
\hline \multicolumn{4}{|l|}{ Gestational age at birth (weeks) } \\
\hline$<34.0$ & 6 & $<5$ & 21 \\
\hline $34.0-36.6$ & 15 & $<15$ & 22 \\
\hline$\geq 37.0$ & 79 & 85 & 57 \\
\hline \multicolumn{4}{|l|}{ 5-min Apgar scores } \\
\hline$<7$ & 13 & 5 & 48 \\
\hline$\geq 7$ & 87 & 95 & 52 \\
\hline \multicolumn{4}{|c|}{ Major non-cardiac congenital anomalies } \\
\hline Yes & 6 & $<5$ & 24 \\
\hline No & 94 & $<100$ & 76 \\
\hline \multicolumn{4}{|l|}{ Prenatal care } \\
\hline Began 1st or 2nd trimester & $<100$ & $<100$ & $<100$ \\
\hline Began 3rd trimester or none & $<5$ & $<5$ & $<5$ \\
\hline \multicolumn{4}{|l|}{ Maternal age (years) } \\
\hline$<20$ & 7 & 7 & $<10$ \\
\hline $20-34$ & 73 & 73 & 74 \\
\hline$\geq 35$ & 20 & 20 & $<20$ \\
\hline \multicolumn{4}{|l|}{ Maternal race/ethnicity } \\
\hline NH White & 28 & 29 & 23 \\
\hline Hispanic-US born & 23 & 24 & 18 \\
\hline Hispanic-Foreign born & 35 & 33 & 39 \\
\hline NH Asian/Pacific Islander & 5 & $<10$ & $<5$ \\
\hline NH Black & 6 & $<10$ & $<10$ \\
\hline Other & 4 & $<5$ & $<10$ \\
\hline \multicolumn{4}{|l|}{ Maternal education } \\
\hline$<$ High school & 32 & 31 & 36 \\
\hline High school degree & 31 & 31 & 32 \\
\hline$>$ High school & 37 & 38 & 32 \\
\hline \multicolumn{4}{|l|}{ Payer } \\
\hline Government & 59 & 60 & 59 \\
\hline Non-government & 41 & 41 & 41 \\
\hline \multicolumn{4}{|l|}{ Census tract poverty level } \\
\hline$<25$ th percentile & 21 & 22 & 14 \\
\hline 25th-75th percentile & 50 & 49 & 55 \\
\hline$>75$ th percentile & 29 & 29 & 31 \\
\hline \multicolumn{4}{|l|}{ Level of care of birth hospital } \\
\hline Level I/II & 20 & 20 & 20 \\
\hline Level III & 50 & 49 & 55 \\
\hline Level IV & 30 & 32 & 25 \\
\hline \multicolumn{4}{|c|}{ Level of care of birth and transfer hospital } \\
\hline No transfer & 34 & 28 & 59 \\
\hline Level I/II to III/IV & 18 & 18 & 17 \\
\hline
\end{tabular}


Table 1 (continued)

\begin{tabular}{lccc}
\hline & Total & $\begin{array}{l}\text { Infants with } \\
\text { interventions }\end{array}$ & $\begin{array}{l}\text { Infants who died } \\
\text { prior to interven- } \\
\text { tion } \\
\%(n=107)\end{array}$ \\
\hline $\begin{array}{l}\text { Level III/IV to III/IV } \\
\text { Day of life of arrival at transfer hospital }\end{array}$ & 28 & 54 & 23 \\
No transfer & 34 & 28 & 59 \\
Arrived DOL 0-1 & 46 & 49 & $<35$ \\
Arrived DOL $\geq 2$ & 21 & 23 & $<15$ \\
\hline
\end{tabular}

Intervention was defined as any ICD-9-CM code for a surgical or catheter-based intervention within 60 days of life for infants who did not die before that time. In order to adhere to OSHPD requirements that cell sizes less than or equal to 15 be suppressed, we present percentages rather than samples sizes and rounded some percentages to the nearest unit of $5 \%$

NH Non-Hispanic

aRRs were $0.6(0.4-0.8)$ and $0.3(0.1-0.9)$; in the initial analyses, the respective aRRs were 0.7 and 0.6 , and their confidence intervals included 1.0.

\section{Mortality}

Of the 556 cases, $153(28 \%)$ died by 28 days of life and a total of 257 (47\%) died by 1 year of age (Table 4). In total, 77 (41\%) of infants who were not transferred and $76(21 \%)$ of transferred infants died by 28 days of life. Among the 449 infants who received a surgical or catheter-based intervention, $52(12 \%)$ died by 28 days of life and a total of 150 (33\%) died by 1 year of age.

Based on multivariable analysis, mortality by 28 days was more likely for infants of low birthweight (RR 1.50), infants with low 5-min Apgar scores (RR 4.69), and infants with other major non-cardiac congenital anomalies (RR 3.41), and it was less likely for infants born into level IV centers (RR 0.27) and infants who were transferred (RR 0.27 for those who arrived at the destination center on DOL $0-1$ and 0.31 for infants who arrived at the destination center on DOL $\geq 2$ ) (Table 5). Unadjusted analyses also found a higher risk of mortality for preterm infants (RR 2.60) and a lower risk of mortality for infants born to mothers at $<25$ th percentile for census tract poverty level (RR 0.62). RRs for all of these noted factors had $95 \%$ confidence intervals that excluded 1.0. Results were similar after including mortality up to 1 year of life (Supplemental Table 4).

\section{Discussion}

In this study of infants born with HLHS in California, 67\% of infants were transferred from their birth hospital for intervention and $47 \%$ died during infancy. Of the analyzed demographic factors, only the presence of a foreign-born Hispanic mother was associated with decreased likelihood of transfer to a destination hospital. Among infants who were transferred, late transfer (i.e., DOL $\geq 2$ ) was more likely for infants who had low birthweight and were born to US-born Hispanic or black mothers. Mortality was more likely for infants who had low birthweight, low 5-min Apgar scores, and other major non-cardiac congenital anomalies and less likely for infants born into level IV centers and among those who were transferred.

\section{Determinants of Hospital Transfer and Its Timing}

Our study found a higher likelihood of being born in a destination center among infants born to foreign-born Hispanic mothers. Hospital transfer patterns were otherwise not predicted by maternal demographic data. In a large populationbased study of births in Texas from 1996 to 2007, Fixler et al. found no differences in age at referral for treatment of critical congenital heart disease (including HLHS) based on race/ethnicity [13]. To our knowledge, this is the only other study to specifically examine sociodemographic factors as they relate to day of arrival at a cardiac center for neonates with HLHS. The higher likelihood of being born in a destination center for foreign-born Hispanic mothers may reflect geographic patterns of where these mothers live in relation to these hospitals. Further studies are needed to clarify this finding.

A multicenter study in California from 2004 to 2005 found that $61 \%$ of infants with HLHS were diagnosed prenatally [26]. The American Heart Association recommends prenatal assignment of postnatal level of care for prenatally diagnosed cardiac lesions, including the more severe forms of HLHS [27]. In practice, many centers will relocate families to be closer to a cardiac center in preparation for delivery of an infant prenatally diagnosed with HLHS, and infants who are prenatally diagnosed are far more likely to be born into the center of intervention [26]. Racial-ethnic differences in transfer patterns found by our study could be related to a 
Table 2 Predictors of hospital transfer in infants with hypoplastic left heart syndrome born in California from 2006 to 2011

\begin{tabular}{|c|c|c|c|c|}
\hline & $\begin{array}{l}\text { Not transferred } \\
\%(n=124)\end{array}$ & $\begin{array}{l}\text { Transferred } \\
\%(n=325)\end{array}$ & $\begin{array}{l}\text { Crude RR of transfer } \\
(95 \% \mathrm{CI})\end{array}$ & $\begin{array}{l}\text { Adjusted RR of transfer } \\
(95 \% \mathrm{CI})\end{array}$ \\
\hline \multicolumn{5}{|l|}{ Infant sex } \\
\hline Male & 68 & 63 & $0.95(0.84-1.06)$ & \\
\hline Female & 32 & 37 & Reference & \\
\hline \multicolumn{5}{|l|}{ Birthweight (g) } \\
\hline$<2500$ & 15 & 15 & $1.00(0.85-1.17)$ & $1.00(0.85-1.18)$ \\
\hline$\geq 2500$ & 85 & 85 & Reference & Reference \\
\hline \multicolumn{5}{|l|}{ Gestational age at birth (weeks) } \\
\hline$<37$ & 15 & 16 & $1.03(0.88-1.20)$ & \\
\hline$\geq 37.0$ & 86 & 84 & Reference & \\
\hline \multicolumn{5}{|l|}{ 5-min Apgar scores } \\
\hline$<7$ & $<10$ & $<5$ & $0.77(0.54-1.11)$ & $0.72(0.50-1.05)$ \\
\hline$\geq 7$ & $<95$ & $<100$ & Reference & Reference \\
\hline \multicolumn{5}{|c|}{ Major non-cardiac congenital anomalies } \\
\hline Yes & $<5$ & $<5$ & $0.99(0.62-1.58)$ & $0.85(0.53-1.38)$ \\
\hline No & $<100$ & $<100$ & Reference & Reference \\
\hline \multicolumn{5}{|l|}{ Prenatal care } \\
\hline Began 1st or 2 nd trimester & $<100$ & $<100$ & Reference & \\
\hline Began 3rd trimester or none & $<5$ & $<5$ & $1.13(0.85-1.51)$ & \\
\hline \multicolumn{5}{|l|}{ Maternal age (years) } \\
\hline$<20$ & $<5$ & 7 & $1.10(0.91-1.33)$ & $1.07(0.85-1.35)$ \\
\hline $20-34$ & 72 & 74 & Reference & Reference \\
\hline$\geq 35$ & $<25$ & 19 & $0.93(0.79-1.09)$ & $0.89(0.76-1.05)$ \\
\hline \multicolumn{5}{|l|}{ Maternal race/ethnicity } \\
\hline NH White & 23 & 31 & Reference & Reference \\
\hline Hispanic-US born & 24 & 23 & $0.93(0.79-1.07)$ & $0.86(0.72-1.02)$ \\
\hline Hispanic-Foreign born & 40 & 31 & $0.87(0.75-1.00)$ & $0.80(0.68-0.94)^{\mathrm{a}}$ \\
\hline NH Asian/Pacific Islander & $<5$ & 6 & $1.02(0.81-1.28)$ & $1.02(0.78-1.32)$ \\
\hline NH Black & $<10$ & $<10$ & $0.91(0.69-1.20)$ & $0.86(0.65-1.14)$ \\
\hline Other & $<5$ & $<5$ & $0.94(0.69-1.30)$ & $1.02(0.75-1.42)$ \\
\hline \multicolumn{5}{|l|}{ Maternal education } \\
\hline$<$ High school & 36 & 29 & $0.91(0.79-1.06)$ & $0.90(0.78-1.05)$ \\
\hline High school degree & 28 & 32 & Reference & Reference \\
\hline$>$ High school & 36 & 39 & $0.98(0.86-1.12)$ & $0.96(0.79-1.15)$ \\
\hline Government & 50 & 59 & $1.00(0.89-1.12)$ & $1.04(0.88-1.25)$ \\
\hline Non-government & 40 & 41 & Reference & Reference \\
\hline \multicolumn{5}{|l|}{ Census tract poverty level } \\
\hline$<25$ th percentile & 23 & 22 & $1.02(0.88-1.19)$ & $0.96(0.81-1.15)$ \\
\hline 25th-75th percentile & 52 & 47 & Reference & Reference \\
\hline$>75$ th percentile & 25 & 31 & $1.08(0.95-1.23)$ & $1.12(0.98-1.28)$ \\
\hline \multicolumn{5}{|l|}{ Level of care of birth hospital } \\
\hline Level I/II & $<10$ & 25 & Reference & \\
\hline Level III & $<5$ & 65 & $1.07(1.00-1.14)$ & \\
\hline Level IV & 89 & 10 & $0.25(0.18-0.34)^{\mathrm{a}}$ & \\
\hline
\end{tabular}

This analysis includes 449 infants; it excludes 107 infants who died and had no evidence of repair. In order to adhere to OSHPD requirements that cell sizes less than or equal to 15 be suppressed, we present percentages rather than samples sizes and rounded some percentages to the nearest unit of $5 \%$

$N H$ non-Hispanic, $R R$ relative risk, $C I$ confidence interval

${ }^{\mathrm{a}} 95 \% \mathrm{CI}$ excludes 1.0 
Table 3 Predictors of late $(\mathrm{DOL} \geq 2)$ versus early (DOL $0-1)$ hospital transfer in infants with hypoplastic left heart syndrome born in California from 2006 to -2011

\begin{tabular}{|c|c|c|c|c|}
\hline & $\begin{array}{l}\text { Early transfer } \\
\%(n=220)\end{array}$ & $\begin{array}{l}\text { Late transfer } \\
\%(n=105)\end{array}$ & $\begin{array}{l}\text { Crude RR of late transfer } \\
(95 \% \mathrm{CI})\end{array}$ & $\begin{array}{l}\text { Adjusted RR of late transfer } \\
(95 \% \mathrm{CI})\end{array}$ \\
\hline \multicolumn{5}{|l|}{ Infant sex } \\
\hline Male & 64 & 61 & $0.91(0.66-1.26)$ & \\
\hline Female & 36 & 39 & Reference & \\
\hline \multicolumn{5}{|l|}{ Birthweight (g) } \\
\hline$<2500$ & 12 & 22 & $1.54(1.09-2.19)^{\mathrm{a}}$ & $1.74(1.20-2.51)^{\mathrm{a}}$ \\
\hline$\geq 2500$ & 88 & 78 & Reference & Reference \\
\hline \multicolumn{5}{|l|}{ Gestational age at birth (weeks) } \\
\hline$<37$ & 17 & $<15$ & $0.83(0.51-1.33)$ & \\
\hline$\geq 37$ & 83 & $<90$ & Reference & \\
\hline \multicolumn{5}{|l|}{ 5-min Apgar scores } \\
\hline$<7$ & $<5$ & $<5$ & $0.71(0.26-1.93)$ & $0.56(0.20-1.58)$ \\
\hline$\geq 7$ & $<100$ & $<100$ & Reference & Reference \\
\hline \multicolumn{5}{|c|}{ Major non-cardiac congenital anomalies } \\
\hline Yes & $<5$ & $<5$ & $0.62(0.11-3.58)$ & $0.77(0.13-4.51)$ \\
\hline No & $<100$ & $<100$ & Reference & Reference \\
\hline \multicolumn{5}{|l|}{ Prenatal care } \\
\hline Began 1st or 2nd trimester & $<100$ & $<100$ & Reference & \\
\hline Began 3rd trimester or none & $<5$ & $<5$ & $1.39(0.66-2.94)$ & \\
\hline \multicolumn{5}{|l|}{ Maternal age (years) } \\
\hline$<20$ & 7 & $<10$ & $1.22(0.70-2.11)$ & $1.45(0.81-2.58)$ \\
\hline $20-34$ & 76 & 71 & Reference & Reference \\
\hline$\geq 35$ & 18 & $<25$ & $1.17(0.80-1.72)$ & $1.05(0.70-1.58)$ \\
\hline \multicolumn{5}{|l|}{ Maternal race/ethnicity } \\
\hline NH White & 34 & 26 & Reference & Reference \\
\hline Hispanic-US born & 22 & 27 & $1.38(0.89-2.13)$ & $1.69(1.04-2.72)^{\mathrm{a}}$ \\
\hline Hispanic-Foreign born & 34 & 25 & $0.96(0.61-1.53)$ & $1.17(0.70-1.93)$ \\
\hline NH Asian/Pacific Islander & $<10$ & $<10$ & $1.38(0.70-2.70)$ & $1.42(0.72-2.79)$ \\
\hline NH Black & $<5$ & $<15$ & $2.42(1.50-3.90)^{\mathrm{a}}$ & $2.45(1.41-4.27)^{\mathrm{a}}$ \\
\hline Other & $<5$ & $<10$ & $2.04(1.09-3.83)^{\mathrm{a}}$ & $1.44(0.75-2.80)$ \\
\hline \multicolumn{5}{|l|}{ Maternal education } \\
\hline$<$ High school & 31 & 25 & $0.95(0.61-1.48)$ & $0.97(0.63-1.50)$ \\
\hline High school degree & 34 & 29 & Reference & Reference \\
\hline$>$ High school & 35 & 47 & $1.35(0.93-1.96)$ & $1.46(0.97-2.19)$ \\
\hline \multicolumn{5}{|l|}{ Payer } \\
\hline Government & 62 & 53 & $0.78(0.57-1.07)$ & $0.75(0.51-1.11)$ \\
\hline Non-government & 38 & 47 & Reference & Reference \\
\hline \multicolumn{5}{|l|}{ Census tract poverty level } \\
\hline$<25$ th percentile & 23 & 21 & $0.96(0.63-1.46)$ & $0.76(0.48-1.19)$ \\
\hline 25th-75th percentile & 48 & 47 & Reference & Reference \\
\hline$>75$ th percentile & 30 & 32 & $1.08(0.76-1.54)$ & $1.07(0.72-1.60)$ \\
\hline \multicolumn{5}{|l|}{ Level of care of birth hospital } \\
\hline Level I/II & $<30$ & 21 & Reference & \\
\hline Level III & 67 & 62 & $1.13(0.75-1.70)$ & \\
\hline Level IV & $<10$ & 17 & $2.07(1.29-3.31)^{\mathrm{a}}$ & \\
\hline
\end{tabular}

This analysis includes 325 infants who were transferred and underwent intervention. In order to adhere to OSHPD requirements that cell sizes less than or equal to 15 be suppressed, we present percentages rather than samples sizes and rounded some percentages to the nearest unit of $5 \%$ $N H$ non-Hispanic, $R R$ relative risk, $C I$ confidence interval ${ }^{\mathrm{a}} 95 \% \mathrm{CI}$ excludes 1.0 
Table 4 Survival among infants born with hypoplastic left heart syndrome in California from 2006 to 2011, based on transfer status and whether they had an intervention

\begin{tabular}{|c|c|c|c|c|}
\hline & Not transferred & $\begin{array}{l}\text { Early transfer } \\
\text { (arrived DOL } \\
0-1)\end{array}$ & $\begin{array}{l}\text { Late trans- } \\
\text { fer }(\text { arrived } \\
\text { DOL } \geq 2)\end{array}$ & Total \\
\hline & $\%(n=187)$ & $\%(n=253)$ & $\%(n=116)$ & $n=556$ \\
\hline Infants who died before intervention ${ }^{a}$ & 34 & 13 & $<10$ & 19 \\
\hline Infants who had intervention & 66 & 87 & $<95$ & 81 \\
\hline Survived & 67 & 67 & 65 & 67 \\
\hline Died $0-28$ days & 12 & 12 & $<15$ & 12 \\
\hline Died 29-365 days & 21 & 21 & $<25$ & 22 \\
\hline All infants & 100 & 100 & 100 & 100 \\
\hline Survived & 44 & 59 & 59 & 54 \\
\hline Death 0-28 days & 41 & 21 & 19 & 28 \\
\hline Death 29-365 days & 14 & 20 & 22 & 19 \\
\hline
\end{tabular}

${ }^{a}$ Infants who died without intervention within 60 days of life (infants who survived $>60$ days without intervention were excluded from the analysis). In order to adhere to OSHPD requirements that cell sizes less than or equal to 15 be suppressed, we present percentages rather than samples sizes and rounded some percentages to the nearest unit of $5 \%$ difference in prenatal detection, but prior studies have not directly associated race/ethnicity with prenatal diagnosis [26, 28, 29]. Our datasets do not have information on timing of cardiac diagnosis. However, the vast majority of mothers in our study began prenatal care before the third trimester and HLHS can be diagnosed on routine second trimester ultrasound, suggesting that many of the infants in our study could have been diagnosed prenatally. Many studies have associated race/ethnicity with disparities in prenatal care for all infants, not just those with congenital heart disease; infants born to black mothers have higher rates of preterm birth [30], even when accounting for socioeconomic status [31]. It is unknown if these inequities in prenatal care led to differences in prenatal planning for the mothers in our study.

Timing of transfer was delayed for neonates born to USborn Hispanic and non-Hispanic black mothers. Further studies are needed to determine what types of factors may be responsible for these differences, such as patterns of residential location relative to the location of cardiac centers or differences in management decisions from a clinician or patient perspective. In addition, infants of low birthweight were more likely to be transferred later. This may reflect the correlation between low birthweight and preterm delivery; there is a wide differential diagnosis for preterm infants presenting in extremis and it may take time to make the diagnosis of cardiac disease requiring transfer. This delay may also reflect the time needed to stabilize a low birthweight or preterm infant prior to transfer.

Given the limitations of our datasets, we cannot comment on timing of palliation in patients, but we can posit that delay in transfer may lead to delays in surgical timing. In a single-center study, Anderson, et al. found that delayed surgical timing in infants with HLHS was associated with increased odds of major morbidity and health care costs
[17]. In a single-center study in New York from 2005 to 2014, Swartz et al. found a younger age of operation, but longer postoperative length of stay and no difference in mortality for infants requiring cardiac surgery who were born into the cardiac center compared to those who were transferred in [32]. Further investigations are needed to determine if a delay in transfer is associated with other factors such as postoperative length of stay, ventilator days, and morbidities such as sepsis and necrotizing enterocolitis among infants with HLHS. These data were not available for the current analysis.

\section{Mortality}

Of 556 total cases, $28 \%$ died within the first month of life. This is consistent with prior studies of neonatal mortality in HLHS [2-4], but higher than that reported by the multicenter, prospective Single Ventricle Reconstruction (SVR) Trial (11.5\%) [33]. Our finding of $47 \%$ mortality by 1 year of life is also higher than the $29 \%$ 1-year mortality reported by the SVR trial [34].

Despite the association of race/ethnicity with timing of transfer, it was not associated with mortality in our cohort, either in the neonatal period or at 1 year of life. A 2018 study by Peyvandi et al. examined infants with HLHS or dextroTransposition of the great arteries and found that infants with Hispanic mothers had a higher risk of a poor outcome (a composite outcome defined by the authors which included mortality) [35]. The authors did not explore the differences by maternal birthplace. We did not compare all Hispanic mothers to other race/ethnicities.

We did find that transfer was associated with a lower risk of mortality. In contrast to our finding, Morris et al. reported a strong association between birth far from a cardiac center 
Table 5 Predictors of neonatal mortality in infants with hypoplastic left heart syndrome born in California from 2006 to 2011

\begin{tabular}{|c|c|c|c|c|}
\hline & $\%(n=403)$ & $\%(n=153)$ & $\begin{array}{l}\text { Crude RR of neo- } \\
\text { natal mortality } \\
(95 \% \mathrm{CI})\end{array}$ & $\begin{array}{l}\text { Adjusted RR of } \\
\text { neonatal mortal- } \\
\text { ity } \\
(95 \% \mathrm{CI})\end{array}$ \\
\hline \multicolumn{5}{|l|}{ Infant sex } \\
\hline Male & 64 & 56 & $0.75(0.55-1.03)$ & $0.90(0.65-1.26)$ \\
\hline Female & 35 & 44 & Reference & Reference \\
\hline \multicolumn{5}{|l|}{ Birthweight (g) } \\
\hline$<2500$ & 16 & 43 & $3.02(2.19-4.17)^{\mathrm{a}}$ & $1.50(1.01-2.22)^{\mathrm{a}}$ \\
\hline$\geq 2500$ & 84 & 58 & Reference & Reference \\
\hline \multicolumn{5}{|l|}{ Gestational age at birth (weeks) } \\
\hline$<37$ & 15 & 35 & $2.60(1.86-3.62)^{\mathrm{a}}$ & \\
\hline$\geq 37.0$ & 85 & 65 & Reference & \\
\hline \multicolumn{5}{|l|}{ 5-min Apgar scores } \\
\hline$<7$ & 5 & 35 & $6.50(4.64-9.11)^{\mathrm{a}}$ & $4.69(3.08-7.16)^{\mathrm{a}}$ \\
\hline$\geq 7$ & 95 & 65 & Reference & Reference \\
\hline \multicolumn{5}{|c|}{ Major non-cardiac congenital anomalies } \\
\hline Yes & $<5$ & 18 & $7.79(5.12-11.8)^{\mathrm{a}}$ & $3.41(2.04-5.69)^{\mathrm{a}}$ \\
\hline No & $<100$ & 82 & Reference & Reference \\
\hline \multicolumn{5}{|l|}{ Prenatal care } \\
\hline Began 1st or 2nd trimester & $<100$ & $<100$ & Reference & \\
\hline Began 3rd trimester or none & $<5$ & $<5$ & $1.44(0.59-3.50)$ & \\
\hline \multicolumn{5}{|l|}{ Maternal age (years) } \\
\hline$<20$ & 7 & $<10$ & $0.89(0.47-1.69)$ & $0.77(0.39-1.49)$ \\
\hline $20-34$ & 73 & 76 & Reference & Reference \\
\hline$\geq 35$ & 20 & $<20$ & $0.84(0.56-1.28)$ & $0.72(0.47-1.12)$ \\
\hline \multicolumn{5}{|l|}{ Maternal race/ethnicity } \\
\hline NH White & 29 & 24 & Reference & Reference \\
\hline Hispanic-US born & 25 & 17 & $0.85(0.52-1.40)$ & $0.80(0.47-1.36)$ \\
\hline Hispanic-Foreign born & 33 & 39 & $1.33(0.88-2.01)$ & 1.27 (0.77-2.09) \\
\hline NH Asian/Pacific Islander & 5 & $<10$ & $1.25(0.58-2.69)$ & $2.11(0.95-4.65)$ \\
\hline NH Black & $<5$ & $<10$ & $1.85(1.00-3.42)$ & $1.72(0.89-3.31)$ \\
\hline Other & $<5$ & $<10$ & $1.81(0.87-3.75)$ & $0.93(0.43-2.03)$ \\
\hline \multicolumn{5}{|l|}{ Maternal education } \\
\hline$<$ High school & 31 & 34 & $1.01(0.68-1.48)$ & $0.93(0.61-1.43)$ \\
\hline High school degree & 30 & 33 & Reference & Reference \\
\hline$>$ High school & 39 & 33 & $0.83(0.56-1.23)$ & $0.74(0.47-1.15)$ \\
\hline \multicolumn{5}{|l|}{ Payer } \\
\hline Government & 58 & 63 & $1.18(0.84-1.63)$ & $1.04(0.69-1.57)$ \\
\hline Non-government & 42 & 37 & Reference & Reference \\
\hline \multicolumn{5}{|l|}{ Census tract poverty level } \\
\hline$<25$ th percentile & 23 & 14 & $0.62(0.39-0.99)^{\mathrm{a}}$ & $0.68(0.41-1.12)$ \\
\hline 25th-75th percentile & 49 & 53 & Reference & Reference \\
\hline$>75$ th percentile & 28 & 33 & $1.04(0.73-1.48)$ & $0.87(0.60-1.26)$ \\
\hline \multicolumn{5}{|l|}{ Level of care of birth hospital } \\
\hline Level I/II & 20 & 20 & Reference & Reference \\
\hline Level III & 48 & 54 & $1.08(0.72-1.63)$ & $0.89(0.57-1.39)$ \\
\hline Level IV & 32 & 26 & $0.78(0.49-1.25)$ & $0.27(0.15-0.48)^{\mathrm{a}}$ \\
\hline \multicolumn{5}{|l|}{ Transferred before repair } \\
\hline Yes & 73 & 50 & $0.42(0.31-0.58)^{\mathrm{a}}$ & \\
\hline No & 27 & 50 & Reference & \\
\hline Day of life of arrival at repair 1 & & & & \\
\hline
\end{tabular}


Table 5 (continued)

\begin{tabular}{|c|c|c|c|c|}
\hline & Survived & Died & $\begin{array}{l}\text { Crude RR of neo- } \\
\text { natal mortality }\end{array}$ & $\begin{array}{l}\text { Adjusted RR of } \\
\text { neonatal mortal- } \\
\text { ity }\end{array}$ \\
\hline & $\%(n=403)$ & $\%(n=153)$ & $(95 \% \mathrm{CI})$ & $(95 \% \mathrm{CI})$ \\
\hline No transfer & 27 & 50 & Reference & Reference \\
\hline Arrived DOL 0-1 & 49 & 35 & $0.44(0.31-0.63)^{\mathrm{a}}$ & $0.27(0.17-0.43)^{\mathrm{a}}$ \\
\hline Arrived DOL $\geq 2$ & 23 & 14 & $0.37(0.23-0.60)^{\mathrm{a}}$ & $0.31(0.17-0.55)^{\mathrm{a}}$ \\
\hline
\end{tabular}

Neonatal mortality was defined as death within the first 28 days of life. In order to adhere to OSHPD requirements that cell sizes less than or equal to 15 be suppressed, we present percentages rather than samples sizes and rounded some percentages to the nearest unit of $5 \%$

$N H$ non-Hispanic, $R R$ relative risk, $C I$ confidence interval

${ }^{\mathrm{a}} 95 \% \mathrm{CI}$ excludes 1.0

and neonatal mortality in neonates with HLHS [3]. Kaltman et al., recently identified an association between maternal proximity to a top 50 cardiac center and better survival in infants with congenital heart disease [36]. However, others have reported no differences in mortality based on birth location for infants with HLHS or other ductal-dependent lesions [11, 12, 37, 38]. The protective effect of transfer found in our study could be explained by a greater propensity for high-risk infants to be delivered into the center of intervention; other studies have confirmed that mothers carrying infants with a prenatal diagnosis of complex congenital heart disease were more likely to deliver in a major cardiac center [26].

\section{Limitations}

This is a large, population-based study over a 6-year time span in the most populous state in the country and is consistent with prior studies of infants with HLHS. Of the 449 patients included in our primary analysis, the majority were male and of normal birthweight and gestational age, consistent with prior large studies of neonates with HLHS [3, 28]. A total of 33 infants (6\%) had a major, non-cardiac congenital anomaly, also consistent with prior studies [28].

Despite these strengths, our study has several limitations. Primarily, the available data are limited in their ability to capture a patient's diagnosis, prenatal diagnosis status, severity of illness, and interventions. Moreover, validation of the available data was not possible. By using CPQCC data, a prospectively collected dataset, we hoped to define our cases more rigorously than with ICD-9 codes, since CPQCC data are collected within NICUs with clear guidelines. We checked our case ascertainment by confirming OSHPD codes for HLHS. Of the 706 CPQCC cases coded for HLHS, 73\% $(n=515)$ also had an ICD-9-CM code for HLHS (746.700) in OSHPD data. It is also possible that not all patients with HLHS in California were entered into CPQCC data; for example, some neonates that were immediately admitted into a cardiovascular intensive care unit and never entered a NICU may not have been captured.

Additionally, based on the nature of ICD-9 coding in OSHPD, we can only identify timing of transfer based on day of arrival at the cardiac center. For example, an infant born at 11:00 p.m. and transferred at 1:00 a.m. the following morning would be counted as an infant transferred on DOL 1, whereas an infant born at 12:01 a.m. and transferred at 1:00 a.m. the following day would be counted the same way. The definition of transfer also cannot account for transfer to a "co-located" hospital, meaning birth at a women's hospital affiliated with a certain children's hospital with a plan for immediate transfer to the children's hospital; these infants would still be counted as "transferred." We therefore combined all infants transferred on DOL 0 and 1 into one category, instead of two. A more in-depth evaluation of hospital locations, regional networks, and distance from maternal residence would be informative but not feasible within the scope of the current analysis.

We are also limited in our ability to define the hospital courses of the 107 infants who died prior to any intervention. We did find that the majority of these infants $(n=63,59 \%)$ were not transferred, and the majority (60\%) died within the first week of life. Sub-analyses on only these infants who died prior to intervention did not identify significant demographic associations with whether or not they were transferred. Including them in a secondary analysis did not significantly alter our findings (see Supplemental Tables 2, $3,4)$. Of note, $24 \%$ of these 107 infants carried a diagnosis of an extracardiac malformation compared to $<5 \%$ of those who underwent an intervention. These 107 infants may include those who were elected for comfort care only by their families, infants with the most severe forms of the disease, infants who died prior to intervention due to management at lower level centers without access to subspecialty cardiac care, or infants with other cardiac diagnoses. Our struggle to determine what happened to these infants speaks to a lack of "best practices" in the literature of how to deal with such a subgroup, as well as the limited available data. 
Despite these limitations, our study is strengthened by the large, racial-ethnically diverse population captured in our analysis and offers new insight into the relationship between transfer patterns and sociodemographic characteristics in infants with HLHS.

\section{Conclusions}

Among neonates with HLHS born in California from 2006 to $2011,67 \%$ of infants were transferred from their birth hospital for intervention, 28\% died as neonates and 47\% died by 1 year of life. Among infants who were transferred to a destination cardiac center, infants born to US-born Hispanic and black mothers were more likely to be transferred late. While we did not associate timing of transfer with mortality, a wealth of prior studies have reported an association between race/ethnicity and mortality. Future studies should further investigate timing of transfer and morbidities in this population and hopefully offer more insight into the factors predicting transfer in infants with HLHS.

Supplementary Information The online version of this article (https:// doi.org/10.1007/s00246-021-02561-w) contains supplementary material, which is available to authorized users.

Acknowledgements We thank the California Environmental Health Tracking Program (CEHTP) Geocoding Service for geocoding maternal addresses.

Funding This work was supported by funding from NIH R01 MD007796.

Data Availability Not applicable.

Code Availability Not applicable.

\section{Compliance with Ethical Standards}

Conflict of interest All authors declare that they have no conflicts of interest or financial ties to disclose.

\section{References}

1. Egbe A, Uppu S, Stroustrup A, Lee S, Ho D, Srivastava S (2014) Incidences and sociodemographics of specific congenital heart diseases in the United States of America: an evaluation of hospital discharge diagnoses. Pediatr Cardiol 35(6):975-982

2. Kane JM, Canar J, Kalinowski V, Johnson TJ, Hoehn KS (2016) Management options and outcomes for neonatal hypoplastic left heart syndrome in the early twenty-first century. Pediatr Cardiol 37(2):419-425

3. Morris SA, Ethen MK, Penny DJ et al (2014) Prenatal diagnosis, birth location, surgical center, and neonatal mortality in infants with hypoplastic left heart syndrome. Circulation 129(3):285-292
4. Hirsch JC, Copeland G, Donohue JE, Kirby RS, Grigorescu V, Gurney JG (2011) Population-based analysis of survival for hypoplastic left heart syndrome. J Pediatr 159(1):57-63

5. Siffel C, Riehle-Colarusso T, Oster ME, Correa A (2015) Survival of children with hypoplastic left heart syndrome. Pediatrics 136(4):e864-e870

6. Oster ME, Strickland MJ, Mahle WT (2011) Racial and ethnic disparities in post-operative mortality following congenital heart surgery. J Pediatr 159(2):222-226

7. Dean PN, McHugh KE, Conaway MR, Hillman DG, Gutgesell HP (2013) Effects of race, ethnicity, and gender on surgical mortality in hypoplastic left heart syndrome. Pediatr Cardiol 34(8):1829-1836

8. Nembhard WN, Pathak EB, Schocken DD (2008) Racial/ethnic disparities in mortality related to congenital heart defects among children and adults in the United States. Ethn Dis 18(4):442-449

9. Nembhard WN, Salemi JL, Loscalzo ML, Wang T, Hauser KW (2009) Are black and Hispanic infants with specific congenital heart defects at increased risk of preterm birth? Pediatr Cardiol 30(6):800-809

10. Nembhard WN, Salemi JL, Ethen MK, Fixler DE, Dimaggio A, Canfield MA (2011) Racial/ethnic disparities in risk of early childhood mortality among children with congenital heart defects. Pediatrics 127(5):e1128-e1138

11. Fixler DE, Nembhard WN, Salemi JL, Ethen MK, Canfield MA (2010) Mortality in first 5 years in infants with functional single ventricle born in Texas, 1996 to 2003. Circulation 121(5):644-650

12. Fixler DE, Nembhard WN, Xu P, Ethen MK, Canfield MA (2012) Effect of acculturation and distance from cardiac center on congenital heart disease mortality. Pediatrics 129(6):1118-1124

13. Fixler DE, Xu P, Nembhard WN, Ethen MK, Canfield MA (2014) Age at referral and mortality from critical congenital heart disease. Pediatrics 134(1):e98-e105

14. Kucik JE, Nembhard WN, Donohue P et al (2014) Community socioeconomic disadvantage and the survival of infants with congenital heart defects. Am J Public Health 104(11):e150-e157

15. Kucik JE, Cassell CH, Alverson CJ et al (2014) Role of health insurance on the survival of infants with congenital heart defects. Am J Public Health 104(9):e62-e70

16. Alsoufi B, Manlhiot C, Al-Ahmadi M et al (2011) Older children at the time of the Norwood operation have ongoing mortality vulnerability that continues after cavopulmonary connection. J Thorac Cardiovasc Surg 142(1):142-147.e142

17. Anderson BR, Ciarleglio AJ, Salavitabar A, Torres A, Bacha EA (2015) Earlier stage 1 palliation is associated with better clinical outcomes and lower costs for neonates with hypoplastic left heart syndrome. J Thorac Cardiovasc Surg 149(1):205-210.e201

18. Attar MA, Dechert RE, Schumacher RE (2012) The effect of late preterm birth on mortality of infants with hypoplastic left heart syndrome. Am J Perinatol 29(8):593-598

19. Costello JM, Pasquali SK, Jacobs JP et al (2014) Gestational age at birth and outcomes after neonatal cardiac surgery: an analysis of the Society of Thoracic Surgeons Congenital Heart Surgery Database. Circulation 129(24):2511-2517

20. Sistino JJ, Ellis C Jr (2011) Effects of health disparities on survival after neonatal heart surgery: why should racial, ethnic, gender, and socioeconomic status be included in the risk analysis? J Extra Corpor Technol 43(4):232-235

21. Kancherla V, Ma C, Grant G et al (2019) Factors associated with timeliness of surgical repair among infants with myelomeningocele: California Perinatal Quality Care Collaborative, 2006 to 2011. Am J Perinatol 37(12):1234-1242

22. Frohnert BK, Lussky RC, Alms MA, Mendelsohn NJ, Symonik DM, Falken MC (2005) Validity of hospital discharge data 
for identifying infants with cardiac defects. J Perinatol 25(11):737-742

23. Steiner JM, Kirkpatrick JN, Heckbert SR et al (2018) Identification of adults with congenital heart disease of moderate or great complexity from administrative data. Congenit Heart Dis 13(1):65-71

24. Khan A, Ramsey K, Ballard C et al (2018) Limited accuracy of administrative data for the identification and classification of adult congenital heart disease. J Am Heart Assoc 7(2):e007378

25. American Academy of Pediatrics (2012) Levels of neonatal care. Pediatrics 130(3):587-597

26. Friedberg MK, Silverman NH, Moon-Grady AJ et al (2009) Prenatal detection of congenital heart disease. J Pediatr 155(1):26-31, 31.e21

27. Donofrio MT, Moon-Grady AJ, Hornberger LK et al (2014) Diagnosis and treatment of fetal cardiac disease: a scientific statement from the American Heart Association. Circulation 129(21):2183-2242

28. Atz AM, Travison TG, Williams IA et al (2010) Prenatal diagnosis and risk factors for preoperative death in neonates with single right ventricle and systemic outflow obstruction: screening data from the Pediatric Heart Network Single Ventricle Reconstruction Trial. J Thorac Cardiovasc Surg 140(6):1245-1250

29. Peiris V, Singh TP, Tworetzky W, Chong EC, Gauvreau K, Brown DW (2009) Association of socioeconomic position and medical insurance with fetal diagnosis of critical congenital heart disease. Circ Cardiovasc Qual Outcomes 2(4):354-360

30. Lorch SA, Enlow E (2016) The role of social determinants in explaining racial/ethnic disparities in perinatal outcomes. Pediatr Res 79(1-2):141-147

31. Johnson JD, Green CA, Vladutiu CJ, Manuck TA (2020) Racial disparities in prematurity persist among women of high socioeconomic status. Am J Obstet Gynecol MFM 2(3):100104
32. Swartz MF, Cholette JM, Orie JM, Jacobs ML, Jacobs JP, Alfieris GM (2017) Transfer of neonates with critical congenital heart disease within a regionalized network. Pediatr Cardiol 38(7):1350-1358

33. Tabbutt S, Ghanayem N, Ravishankar C et al (2012) Risk factors for hospital morbidity and mortality after the Norwood procedure: a report from the Pediatric Heart Network Single Ventricle Reconstruction trial. J Thorac Cardiovasc Surg 144(4):882-895

34. Ohye RG, Schonbeck JV, Eghtesady P et al (2012) Cause, timing, and location of death in the Single Ventricle Reconstruction trial. J Thorac Cardiovasc Surg 144(4):907-914

35. Peyvandi S, Baer RJ, Moon-Grady AJ et al (2018) Socioeconomic mediators of racial and ethnic disparities in congenital heart disease outcomes: a population-based study in California. J Am Heart Assoc 7(20):e010342

36. Kaltman JR, Burns KM, Pearson GD, Goff DC, Evans F (2020) Disparities in congenital heart disease mortality based on proximity to a specialized pediatric cardiac center. Circulation 141(12):1034-1036

37. Bennett KM, Scarborough JE, Pappas TN, Kepler TB (2010) Patient socioeconomic status is an independent predictor of operative mortality. Ann Surg 252(3):552-557; discussion 557-558

38. Bennett TD, Klein MB, Sorensen MD, De Roos AJ, Rivara FP (2010) Influence of birth hospital on outcomes of ductal-dependent cardiac lesions. Pediatrics 126(6):1156-1164

Publisher's Note Springer Nature remains neutral with regard to jurisdictional claims in published maps and institutional affiliations. 